\title{
Dr Thomas Radford (1793-1881) of Manchester and obstructed labour
}

\author{
Peter M Dunn
}

Thomas, son of John Radford of Manchester, was born in 1793. In his teens he was apprenticed to Mr William Wood in King Street, where subsequently he practised for many years. In 1818, when he was 25 , he was elected surgeon to the Manchester and Salford LyingIn Hospital and also appointed 'man-midwife for out-districts' to St Mary's Hospital for Women and Children. Later, after obtaining an MD from Heidelberg in 1839 and the FRCP (Edinburgh) he became consulting physician to both hospitals. He also acquired the FRCS, England, in 1852.

Radford's association with St Mary's Hospital spanned 63 years. He was present in 1842 when a colleague, Charles Clay, performed the first operation there for removal of an ovarian tumour. The operation lasted 15 minutes and the tumour weighed $17^{1 / 2} \mathrm{lb}$. The patient made an excellent recovery. It is also of interest that many years later, when he was Chairman of the Board of Management of St Mary's, he noted that there had been two cases of 'lacerated perineum' among 2861 deliveries at the hospital that year (1879). He commented: 'this accident is frequently disgraceful to the practitioner when it happens to an obstetrician or midwife but these cases did not occur in the practice of this hospital but were admitted as patients after the accident had happened'.

Few people, medical or lay, have done more for St Mary's Hospital than Radford. In addition to his professional services, he gave his valuable library, which was especially rich in obstetric works, to the hospital in 1853. He also presented his museum of medical specimens and obstetric instruments with an endowment to provide suitable accommodation and maintenance.

Thomas Radford was a prolific writer, particularly on obstetric subjects. His best known work Observations on the Caesarean Section, Craniotomy and on Other Obstetric Operations was first published in 1865 , with a second edition in $1880 .{ }^{1}$ It is from the second edition that the extracts that follow were taken. In the introduction he stated that his object was to endeavour to gain the approval of both the profession and society for caesarean section on moral as well as medical and social grounds.

With urbanisation and the industrial revolution, malnutrition had become rife

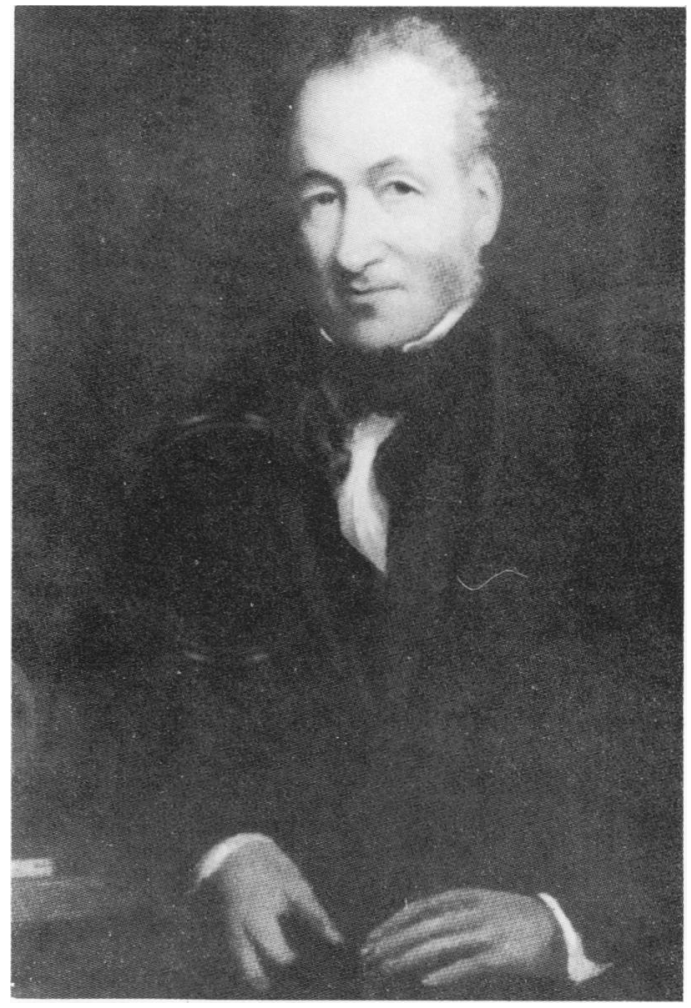

Dr Thomas Radford (1793-1881).

during the 19 th century. Pelvic deformity was commonplace due to childhood rickets and osteomalacia in adult life. Sometimes the pelvic cavity was almost obliterated. When delivery was not possible using the long forceps, the vectis, or by breech extraction, recourse was made to craniotomy, though it carried a maternal mortality of $20 \%$. Even craniotomy was not possible if the true conjugate was less than $2^{\prime \prime}(5 \mathrm{~cm})$, in which case the mother and child usually died after a long, exhausting and painful labour. The only alternative was caesarean section. Dr Radford collected 77 case reports in the UK before 1865. Pelvic deformity due to rickets or obsteomalacia was primarily responsible in $74 \%$ of cases. Only $14 \%$ of the mothers and $59 \%$ of the infants survived. But, as Dr Radford pointed out, this tragic outcome was related to the fact that the operation was only undertaken as a last resort. He made a strong plea that it should in future be used electively when it was clear that vaginal delivery would not be possible. Dr Radford's advice on how 
the caesarean operation should be performed is of considerable interest:

'This operation ought not to be made one of display. There should only be a very few persons present; and the greatest quietude should be afforded to the patient... It is of first importance, when possible, to adopt all such measures as will prepare the patient to undergo this operation, by improving the general health. The bowels should be emptied... the bladder must also be emptied... Frequent examination per vaginam should not be allowed... the operation should be performed on the bed... the temperature of the room should be regulated, and a genial warmth of the atmosphere maintained... we must at once be convinced how important it is to perform (the operation) early... It is a well known fact that little risk comparatively occurs before the waters are discharged... Before the incision is made, the location of the placenta should, if possible, be ascertained, in order to avoid its being wounded... The stethoscope will nearly always... assure ourselves in what vicinity of the uterus the placenta is fixed... The nearer the abdominal incision is made to the central line of the linea alba, the less will be the haemorrhage. The earlier the operation the better for the safety of the mother and child. Chloroform, by leading to uterine inertia and vomiting is an unsafe anaesthetic. Local anaesthesis by spraying the line to be incised is safer... ether is safer... The operation is not very painful after the skin has been incised... The incision should be made on the body of the uterus, because this portion of the organ is eminently contractile, and ought to extend well towards the fundus, but not into it. It ought not, however, to be carried too far down into the cervix uteri... there should be no delay in withdrawing the infant... The placenta, with the membranes, should be also quickly extracted. Protrusion of the intestines is very apt to occur... Every care should be taken by the assistants to repress and retain these viscera... To arrest uterine haemorrhage and prevent its return, suture the uterus with silver wire stitches. Ice is a good remedy for exciting uterine contraction... Ergot is a good preparation to avoid inertia. The abdomen should be thoroughly cleaned of all the blood and amniotic fluid... Septic poisoning is apt to originate in the decomposition of matters that have escaped from the uterus... The after-management of the patient must be conducted on recognised medical and surgical principles... Opium in full doses if required, should be given...'

Although most of Dr Radford's book is devoted to caesarean operation, including the 77 case reports, he also includes an interesting chapter on the use of induced premature labour as a means of avoiding later disproportion:

'The induction of premature labour was first performed by Dr Macaulay in England in the year $1756 \ldots$ notwithstanding its high value, it ought never to be performed without great necessity, nor without having been first well considered and sanctioned by a consultation. It is a simple, safe, and efficacious operation, and if duly performed, infants not to be computed in number would be born alive... it is not intended to supersede the Caesarean section... the great object... is to prevent as far as possible the performance of craniotomy... Most writers assert that (the foetus) is not viable before the end of the seventh month of pregnancy; but I think it will live after a shorter sojourn in the uterus... The following table shows the progressive development of the foetal head... from the $51 / 2$ month up to the 9 th month... The above measurements strikingly show the size of the head will be found greater or less according to the period of pregnancy at which artificial labour is brought on... Before the operation for the induction of premature labour is performed, the obstetrician should have fully acquainted himself with the relative measurements of the head of the infant and the pelvic space through which it has to pass.

So long as the membranes are entire, and the infant is unrestricted in its movement and floating in the liquor amnii, its life is comparatively safe; but, as soon as the water is discharged, it is subject to more hazard, from the compression it must necessarily bear, and especially so if the os uteri be not dilated. If this be true in ordinary labour, it is more decidedly so when it is artificially induced. Besides, there is no other means so effectual in distending the cervix, and in dilating the os uteri, as the membranous bag filled with the liquor amnii, which acts during each pain as a powerful wedge... On these grounds, then, it is of the greatest importance, when labour is artificially brought on, that the membranes should, if possible, be kept entire; and, therefore, those means should be employed which are calculated to accomplish this object.

The old, and perhaps the most common, method of puncturing the membranes, is certain in its effects, although some days frequently elapse before labour ensues. Although I have formerly frequently adopted this plan, yet it is objectionable, on account of depriving the infant of the protective influence of the amnion fluid, \&c. To partly obviate this evil, it has been proposed to carry an instrument through the os uteri and upwards between the uterus and the membranes, before piercing them.

Dr Hamilton passed his finger through the os and upwards between the membranes and the uterus, and then round so as to detach them; and had the utmost confidence in it...

The vaginal douche has the confidence of many obstetricians. It consists of a forcible and continuous stream of water, sometimes warm and sometimes cold, being directed against the os uteri, so as to wash out the mucous plug. Although this is comparatively a safe measure, it is not always certain in 
its effects, and is also somewhat slow in acting... Sponges, prepared so as to easily pass through the os, and left to expand, are comparatively safe, and may sometimes be employed as preparative measures... attempts to dilate the os uteri should be both gentle and gradual, and made to resemble as nearly as possible the method Nature pursues in opening this part. Forcible dilatation, without preparation, is at all times most mischievous.'

Dr Radford also discusses briefly other methods of forestalling the need for either premature induction of labour or caesarean section, namely therapeutic abortion or, even better, sterilisation of the woman by section of her fallopian tubes, as first suggested by Dr James Blundell in the 1820 s.

Thomas Radford married a daughter of the rector of Didsbury, the Rev John Newton. They had one daughter who, sadly, died young. Dr Radford, himself, lived to the ripe old age of 88 .

1 Radford T. Observations on the caesarean section, craniotomy and on other operations. 2nd Ed. London: J \& A Churchill, 1880. 